\title{
Find faults and funds
}

\author{
Seismic risk is poorly known in many places on Earth. To save lives it is necessary - but by no means \\ sufficient - to map the faults that pose a threat more accurately.
}

That an earthquake struck Japan was no surprise. The country, aware of the risk, had prepared for such an emergency, even though the timing, exact location and magnitude of the shaking and ensuing tsunami were unforeseen. Japan can afford state-of-the-art building standards and safety measures. As a result, the death toll from the March catastrophe was far lower than might have been expected from the combined violence of quake and wave. Many other regions, however, are less fortunate in terms of both awareness and wealth.

As highlighted in a Commentary on page 348 of this issue, the deadliest earthquakes last century struck the interiors of continents, rather than the more readily identified seismic risk zones at the boundaries of plates. Earthquakes in any one location are far less frequent within continents, where strain accumulates much more slowly and extends in networks that cover a much larger area. As a result, seismic risk is more easily overlooked and indeed was thought to be low in many of the places hit by last century's destructive events.

The lack of reliable knowledge regarding potential earthquake hazards is exemplified in the Andean region. A Letter on page 380 argues that the seismic risk for the eastern, inland flank of the Andes needs to be revised upwards markedly. According to the analyses presented, the locked section of a fault in the region has been accumulating elastic energy and could unleash an earthquake of up to $M_{\mathrm{w}} 8.9$ if it ruptured in a single event - much larger than the previously suggested maximum of $M_{\mathrm{w}} 7.5$.

Dramatic revisions of our understanding of seismic risk are not the exception (Nature Geosci. 1, 485-487; 2008). In the past, earthquake hazard maps often had to be redrawn, following an unforeseen event of shaking. We need to acknowledge that along broad swathes of the Earth's surface, we are simply in the dark when it comes to potential seismic risk.

Of course, knowing where an earthquake might strike is not enough. Haiti's devastating quake, for instance, did not come without warning, yet the country's limited monetary and administrative resources did not allow a credible and effective effort in raising resilience (Nature 463, 878-879; 2010; Nature Geosci. 3, 740-741; 2010). Similarly, if an efficient tsunami-warning system such as the one established for the Pacific Ocean - had been in place in the poorer Indian Ocean region before December 2004, the number of fatalities resulting from the Sumatra earthquake and tsunami would have been much lower.
But no amount of money can prevent destruction altogether. The death rate was probably as low in Japan as achievable through the best efforts of a country with the political will and sufficient resources to prepare. Still, more than 20,000 people died. And secondary, but nevertheless noteworthy, the Tōhoku earthquake may have been the costliest natural disaster in terms of dollars, not lives - so far (http://go.nature.com/UYgfL6).

The death toll of natural disasters is falling in the developed world as countermeasures and emergency plans are refined, buildings standards raised and protective structures improved. At the same time, the monetary damage of an earthquake rises, essentially because the property at risk is necessarily more valuable in a richer country (http://go.nature.com/ DWqeyo).

There is no option for humans to move out of harm's way and avoid living in places on Earth where the danger of an earthquake may loom. Because we are populating high-risk areas, we need to acknowledge the danger, and continuously strive to protect ourselves as best we can by mapping hazards as well as finding the funds to raise resilience. The magnitude of the destruction seen in Japan serves as a reminder of both the success of this approach and its limits.

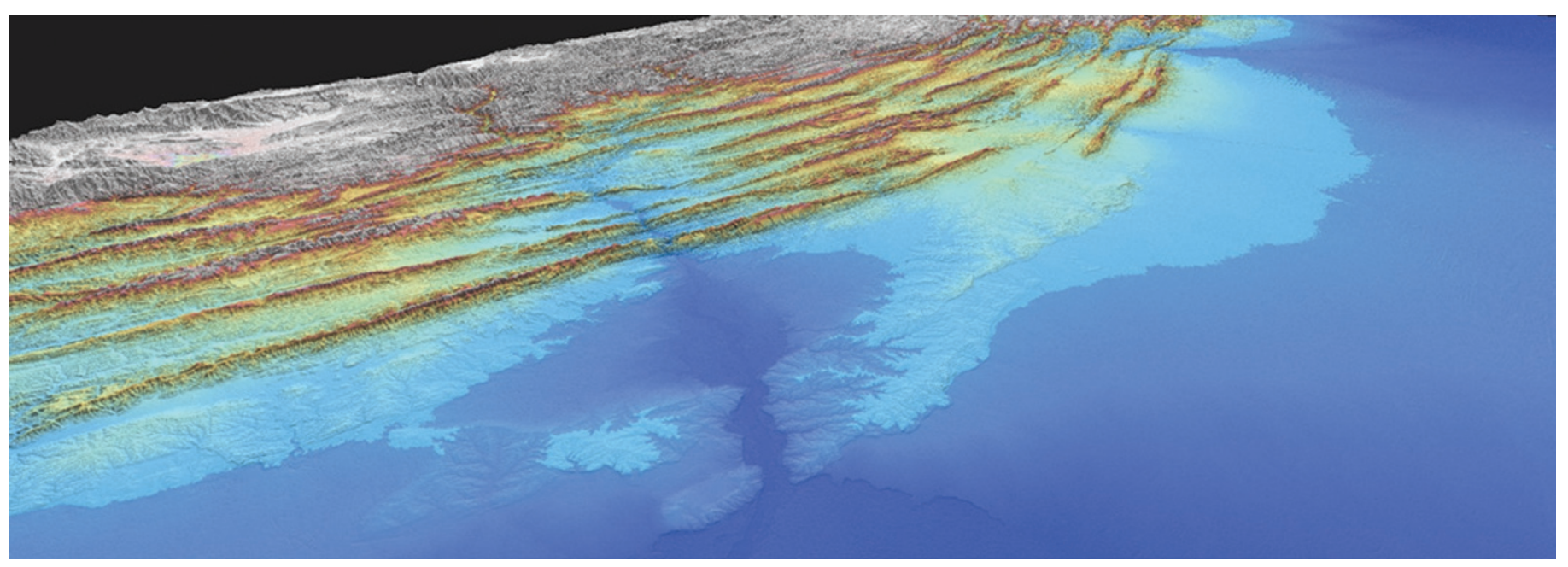

Looking west over the Bolivian Subandes. The slightly elevated region in the foreground is the topographic expression of the Mandeyapecua thrust fault that could, according to Brooks et al. (page 380), slip in a large earthquake. (c) Jonathan Weiss and Ben Brooks, University of Hawaii. 